\title{
Assessment of heart disease knowledge and risk factors among first-generation Filipino Americans residing in Southern Nevada: A cross-sectional survey
}

\author{
Alona D. Angosta ${ }^{1}$, Kirsten E. Speck ${ }^{2}$ \\ University of Nevada, Las Vegas School of Nursing, Las Vegas, Nevada, United States \\ Correspondence: Alona D. Angosta. Address: School of Nursing, University of Nevada, Las Vegas 4505 South Maryland \\ Parkway Box 453018 Las Vegas, Nevada 89154-3018, United States. Email: alona.angosta@unlv.edu
}

Received: December 4, 2013

Accepted: March 17, 2014

Online Published: March 25, 2014

DOI : $10.5430 / c n s . v 2 n 2 p 123$

URL: http://dx.doi.org/10.5430/cns.v2n2p123

\begin{abstract}
Objective: Filipino Americans are the second largest Asian subgroup in the United States and heart disease is their leading cause of death. Despite this, they remain an invisible minority and experience health disparities in cardiovascular health. Prior to implementing and designing health promotion programs, it is important to assess their level of knowledge about heart disease and to identify their risk factors.

Purpose: We examined the baseline knowledge of heart disease among first-generation Filipino Americans and the risk factors prevalent among them.

Method: A convenience sample of 300 Filipino Americans aged 35-75 years completed the Heart Disease Fact Questionnaire to assess their knowledge of heart disease and a researcher-developed questionnaire to assess the heart disease risk factors. Data were collected in Southern Nevada in the fall of 2011. Descriptive statistics, correlations, and multiple regression were used for data analysis.

Result: The sample had an average knowledge score of $82.81 \%$ out of a maximum correct score of $100 \%$. The risk factors prevalent among them included: hypertension (47.7\%), diabetes (14\%), dyslipidemia (27.7\%), overweight (36.7\%), abdominal obesity (80.6\%), smoking (11.7\%), and lack of exercise (48\%).

Conclusion: Heart disease is the leading cause of death among Filipino Americans. In this study, Filipino Americans had adequate knowledge of heart disease but many reported having risk factors. Understanding the behavioral determinants of heart disease knowledge and specific risk factors is helpful in designing effective health prevention strategies. Early screening targeting the younger generation is also important to help detect the risk factors in their earliest stages. The screening results may also induce individuals to take action.
\end{abstract}

\section{Key words}

Coronary heart disease, Filipino Americans, Knowledge, Risk factors

\section{I ntroduction}

Between 2000 and 2010, the Asian American population in the United States (US) increased by $43 \%{ }^{[1]}$. A majority of the growth occurred in the western US; with Nevada having the highest growth of Asian Americans ${ }^{[1]}$. Filipino Americans 
were reported to be the fastest growing Asian immigrants in Nevada and throughout the country ${ }^{[1]}$. According to the US Census Bureau News, there are 3.4 million Filipino Americans living in the US making them the second largest Asian groups in the country ${ }^{[2]}$. Based on the 2007 age-adjusted death rates, Nevada had the 13th highest death rate in the country from cardiovascular diseases ${ }^{[3,4]}$. This data include the mortality rate of Filipino Americans from heart disease ${ }^{[2,5]}$.

Studies indicate that heart disease is prevalent among Filipino Americans than any other ethnic groups ${ }^{[6-13]}$. The rate of hypertension (HTN), diabetes, and dyslipidemia are higher among Filipino Americans than Caucasians, Pacific Islanders, and other Asian populations ${ }^{[9-13]}$. Diet (i.e. foods high in saturated fats, low intake of fruits and vegetables); smoking; and lack of regular exercise have been reported as possible explanations for the poor cardiac health outcomes among Filipino

Americans ${ }^{[6-13]}$. Prior to implementing and designing effective health promotion programs, it is important to assess the level of knowledge about heart disease and to identify the risk factors prevalent among this population. Understanding of heart disease and awareness of risk factors influence judgments and decisions in heart disease prevention and control. The aims of our study were to (a) examine the knowledge of heart disease among first-generation Filipino Americans between the ages of 35-75 years old residing in Southern Nevada, and (b) examine the heart disease risk factors prevalent among this population. This study addressed the following research questions:

- What is the baseline knowledge of heart disease among Filipino Americans?

- What are the risk factors of heart disease prevalent among Filipino Americans?

- Is there a relationship between heart disease knowledge, risk factors, and demographic characteristics of Filipino Americans?

\section{Review of the literature}

Studies focusing on the cardiac health of Filipino Americans are limited. They are mostly related to disparities in the prevalence of heart disease and risk factors. Analyses of these studies are outlined below:

\subsection{Hypertension}

The National Heart, Lung, and Blood Institute (NHLBI) in collaboration with the Asian \& Pacific Islander Health Forum, assessed the cardiovascular health status of 39 Filipinos between 20 and 79 years old living in Daly City, California. They found that $35 \%$ had HTN and $40 \%$ reported having a family member with HTN ${ }^{[14]}$. Ryan et al. ${ }^{[15]}$ compared the prevalence of HTN among 527 Filipinos and 3,176 Caucasians between 56 and 76 years old. They found that Filipinos had a higher incidence of HTN than Caucasians $(79 \%$ vs $69 \%, p \leq 0.0001)$. Ye et al. ${ }^{[9]}$ compared the cardiovascular risk factors among Asian Americans. They also found that HTN was higher among Filipino Americans (23.9\%) than Chinese (16.9\%), Asian Indians (10.4\%), and other Asian American groups (16.3\%); $(p \leq 0.001)$.

\subsection{Diabetes Mellitus}

Type 2 diabetes is a common health problem among Filipino Americans. Kim et al. ${ }^{[12]}$ compared the prevalence of type 2 diabetes in four different ethnic groups $(N=1,257)$ in North Kohala, Hawaii. Their sample consisted of 261 Filipinos, 344 Caucasians, 434 Hawaiians, and 218 Japanese. They found that $20.3 \%$ of Filipinos had type 2 diabetes compared to Caucasians (6.7\%), Hawaiians (19.8\%), and Japanese (21\%). This result is consistent with Ye et al.'s ${ }^{[9]}$ finding. They also found a higher rate of type 2 diabetes among Filipinos when compared to other Asian groups (Filipinos 6.1\%, Chinese 5.5\%, other Asians 3.8\%; $p=0.008$ ). In 2002, Araneta et al. ${ }^{[16]}$ compared the rate of type 2 diabetes between Caucasian women $(n=379)$ and Filipino women $(n=294)$. They found a higher rate of type 2 diabetes among Filipino women $(36.4 \%)$ than Caucasian women (8.7\%). 


\subsection{Dyslipidemia}

Ryan et al. ${ }^{[15]}$ also compared the rate of dyslipidemia between Filipino Americans and Caucasians. In their study, they found that dyslipidemia was higher among Filipino Americans (34.7\%) than Caucasians $(24.1 \% ; p=<0.0001)$. This result is consistent with Araneta and Barrett-Connor's finding ${ }^{[1]}$. They also found a higher rate of dyslipidemia among Filipino women $(31 \%)$ when compared to Caucasian women (19\%).

\subsection{Smoking}

Tobacco use is prevalent among Filipino Americans. Data from a community sample of 318 Filipino men between 40 and 75 years old living in Los Angeles, California, indicated that $69 \%$ have been exposed to cigarette use, $35 \%$ reported that they were current smokers, and $34 \%$ were former smokers ${ }^{[17]}$.This finding is consistent with Ye et al.'s ${ }^{[9]}$ study. In their sample of 77,267 Asian Americans, Filipinos had a higher percentage of tobacco use (17.7\%) than Chinese (9.2\%) and Asian Indians $(7.6 \% ; p \leq 0.001)$.

\section{Methods}

\subsection{Design, sample, and setting}

Our study used a cross-sectional survey design. The Institutional Review Board at the University of Nevada, Las Vegas approved our study protocol prior to commencement of any research activities. Data were collected in Southern Nevada from September to December 2011. A convenience sample of 300 Filipino Americans participated in our study. The inclusion criteria were Filipino Americans between the ages of 35 and 75 years old: who could read, speak, write and understand English. The exclusion criteria were those with (a) a history of heart disease who received counseling in the past from their health care providers; (b) with a history of memory or neurological impairments, or both, that would limit reading, talking, or writing; and (c) who had participated in a study similar to this.

\subsection{Procedures}

To reach a greater number of Filipino Americans, we posted flyers ${ }^{[18]}$ in Filipino stores, supermarkets, and fast-food restaurants. We also announced our study during Filipino events. Approximately 25 Filipino Americans were recruited through this method and met the study criteria. We also set up a table inside a Filipino restaurant on weekdays (i.e. Monday-Thursday) and sometimes on weekends, during lunch times. The table was in a private section of the restaurant. We used this area for consent signing and completion of the questionnaires. Over 300 participants were approached as they entered the restaurant, 275 met the criteria and completed the questionnaires. All in all, 300 Filipino Americans met the study criteria and completed the questionnaires. Completion of the forms was about 10 to 15 minutes long. Each participant received $\$ 5.00$ after completing the questionnaires.

\subsection{Measurements}

Knowledge of heart disease was measured using the Heart Disease Fact Questionnaire (HDFQ). The original HDFQ was developed by Wagner and colleagues ${ }^{[19]}$ and with permission; it was modified to fit the objectives of this study. The modified HDFQ is a 21 -item, true or false, cognitive measure about heart disease knowledge ${ }^{[19,20]}$. It has been used in prior studies and tested for reliability and validity ${ }^{[6,19,20]}$. The modified questionnaire demonstrated face and content validity ${ }^{[6]}$. Cronbach's alpha for bivariate data (correct vs. incorrect) was .734 and for actual item choice (true, false, I don't know) was .742, indicating a good reliability (see Table 1). Total scores for heart disease knowledge were calculated by summing the total number of correct answers, with higher scores indicating more knowledge ${ }^{[6,19,20]}$. The demographic data included age, place of birth, gender, marital and employment status, income and education status, living arrangements, and health insurance status. The presence of heart disease risk factors was obtained from a questionnaire 
developed by the primary investigator. Questions were related to the self-reported presence of HTN, diabetes, dyslipidemia, and whether the participants were overweight, smokers, or did not exercise.

Table 1. Measures of heart disease knowledge $(\mathrm{N}=300)$

\begin{tabular}{|c|c|c|c|}
\hline Question & ${ }^{\mathrm{a}}$ True & ${ }^{b}$ False & 'I don't know \\
\hline 1. A person always knows when they have coronary heart disease & $68(22.7)$ & $199(66.3)^{*}$ & $33(11.0)$ \\
\hline $\begin{array}{l}\text { 2. If you have a family history of coronary heart disease, you are at risk for } \\
\text { developing heart disease }\end{array}$ & $257(85.7)^{*}$ & $22(7.3)$ & $21(7.0)$ \\
\hline 3. The older a person is, the greater their risk of having coronary heart disease & $232(77.3)^{*}$ & $55(18.3)$ & $13(4.3)$ \\
\hline 4. Smoking is a risk factor for coronary heart disease & $281(93.7)^{*}$ & $11(3.7)$ & $8(2.7)$ \\
\hline $\begin{array}{l}\text { 5. A person who stops smoking will lower their risk of developing coronary } \\
\text { heart disease }\end{array}$ & $254(84.7)^{*}$ & $29(9.7)$ & $17(5.7)$ \\
\hline 6. High blood pressure is a risk factor for developing coronary heart disease & $281(93.7)^{*}$ & $5(1.7)$ & $14(4.7)$ \\
\hline $\begin{array}{l}\text { 7. Keeping blood pressure under control will reduce a person's risk for } \\
\text { developing heart disease }\end{array}$ & $285(95.0)^{*}$ & $8(2.7)$ & $7(2.3)$ \\
\hline 8. High cholesterol is a risk factor for developing coronary heart disease & $281(93.7)^{*}$ & $9(3.0)$ & $10(3.3)$ \\
\hline 9. If your "good" cholesterol (HDL) is high, you are at risk for heart disease & $74(24.7)$ & $180(60.0)^{*}$ & $46(15.3)$ \\
\hline 10. If your "bad" cholesterol (LDL) is high, you are at risk for heart disease & $234(78.0)^{*}$ & $27(9.0)$ & $39(13.0)$ \\
\hline 11. Eating fatty foods does not affect blood cholesterol levels & $42(14.0)$ & $249(83.0)^{*}$ & $9(3.0)$ \\
\hline 12. Being overweight increases a person's risk for coronary heart disease & $280(93.3)^{*}$ & $4(1.3)$ & $16(5.3)$ \\
\hline $\begin{array}{l}\text { 13. Regular physical activity will lower a person's chance of getting heart } \\
\text { disease }\end{array}$ & $282(94.0)^{*}$ & $13(4.3)$ & $5(1.7)$ \\
\hline $\begin{array}{l}\text { 14. Only exercising at a gym or in an exercise class will lower a person's } \\
\text { chance of developing heart disease }\end{array}$ & $57(19.0)$ & $238(79.3)^{*}$ & $5(1.7)$ \\
\hline $\begin{array}{l}\text { 15. Walking and gardening are considered exercise that will help lower a } \\
\text { person's chance of developing heart disease }\end{array}$ & $195(65.0)^{*}$ & $95(31.7)$ & $10(3.3)$ \\
\hline 16. Diabetes is a risk factor for developing coronary heart disease & $249(83.0)^{*}$ & $17(5.7)$ & $34(11.3)$ \\
\hline 17. High blood sugar makes the heart work harder & $232(77.3)^{*}$ & $17(5.7)$ & $51(17.0)$ \\
\hline $\begin{array}{l}\text { 18. A person who has diabetes can reduce their risk of developing coronary } \\
\text { heart disease if they keep their blood sugar levels under control }\end{array}$ & $204(68.0)^{*}$ & $35(11.7)$ & $61(20.3)$ \\
\hline $\begin{array}{l}\text { 19. Abdominal obesity (fat belly) is a risk factor for developing coronary } \\
\text { heart disease }\end{array}$ & $254(84.7)^{*}$ & $16(5.3)$ & $30(10.0)$ \\
\hline $\begin{array}{l}\text { 20. Stress may cause an increase in blood sugar, blood pressure, and } \\
\text { cholesterol levels }\end{array}$ & $285(95.0)^{*}$ & $7(2.3)$ & $8(2.7)$ \\
\hline $\begin{array}{l}\text { 21. Slow deep breaths, counting to } 10 \text { before speaking, going for a walk, are } \\
\text { examples of stress stoppers }\end{array}$ & $264(88.0)^{*}$ & $8(2.7)$ & $28(9.3)$ \\
\hline
\end{tabular}

Note. ${ }^{*}=$ Correct answers, ${ }^{\mathrm{a}, \mathrm{b}, \mathrm{c}}=$ Frequency and percent

Cronbach's alpha for bivariate data (correct vs. incorrect) .734, and for actual item choice (true, false, I don't know) .742.

\subsection{Analysis}

Data were analyzed using the IBM SPSS Statistics Version 19. Descriptives and percentages were used to summarize the demographic data, and frequency was used to describe the presence of heart disease risk factors and the knowledge scores. ANOVA, point-biseral and Pearson' correlations were used to examine the relationships between heart disease knowledge and demographic data. Chi-square analysis was used to determine differences between those who lived alone or with 
someone (i.e., spouse, children, friend). Logistic and multiple regressions were used to examine the relationships and predictors of heart disease knowledge scores and risk factors.

\section{Results}

\subsection{Demographics}

The mean age of the sample was 50.8 years. Seventy-nine percent were married, $71 \%$ were employed, $82 \%$ had health insurance, and 50\% were college graduates. Most participants were living with their spouse, children, and relatives. All participants were born in the Philippines and the average length of residency in the US was 24 years.

\subsection{Heart disease knowledge}

The sample had an average heart disease knowledge score of $80.81 \%$ out of a maximum score of $100 \%(M=17.39, S D=$ 3.03, Min $=1.00, \operatorname{Max}=21$ ). Table 1 displays the HDFQ scores on each of the questions asked.

The relationships between heart disease knowledge and the demographic data are displayed in Table 2 .

Table 2. Relationships between heart disease knowledge scores and demographics $(N=300)$

\begin{tabular}{|c|c|c|c|c|c|c|}
\hline Measure & Group & $\%$ & $M$ & $S D$ & Test Statistic & $P$ - value \\
\hline \multirow{4}{*}{ Age } & $32-41$ years & 20 & \multirow{4}{*}{50.8} & \multirow{4}{*}{10.02} & \multirow{4}{*}{$r=.153$} & \multirow{4}{*}{.008} \\
\hline & $42-49$ years & 30 & & & & \\
\hline & $50-57$ years & 25 & & & & \\
\hline & $58-75$ years & 25 & & & & \\
\hline \multirow{2}{*}{ Gender } & Males & 49 & & & \multirow{2}{*}{$r_{\mathrm{pb}}=.024$} & \multirow{2}{*}{.680} \\
\hline & Females & 51 & & & & \\
\hline \multirow{2}{*}{ Marital Status } & Not Married & 21 & & & \multirow{2}{*}{$r_{\mathrm{pb}}=.144$} & \multirow{2}{*}{.012} \\
\hline & Married & 79 & & & & \\
\hline \multirow{2}{*}{$\begin{array}{l}\text { Employment } \\
\text { Status }\end{array}$} & Unemployed & 29 & & & \multirow{2}{*}{$r_{\mathrm{pb}}=.021$} & \multirow{2}{*}{.717} \\
\hline & Employed & 71 & & & & \\
\hline \multirow[t]{2}{*}{ Education Level } & $\begin{array}{l}\text { Completed Grade School and/or High } \\
\text { school }\end{array}$ & 50 & & & \multirow[t]{2}{*}{$r_{\mathrm{pb}}=.172$} & \multirow[t]{2}{*}{.003} \\
\hline & Completed College & 50 & & & & \\
\hline \multirow{3}{*}{ Annual Income } & $>\$ 30,000$ & 23 & & & \multirow{3}{*}{$F(14.285)=1.53$} & \multirow{3}{*}{.101} \\
\hline & $\$ 30,000-\$ 49,000$ & 47 & & & & \\
\hline & $>\$ 50,000$ & 30 & & & & \\
\hline \multirow{3}{*}{$\begin{array}{l}\text { Living } \\
\text { Arrangement }\end{array}$} & Alone, with Relative and their & 38 & & & \multirow{3}{*}{$F(14.285)=.954$} & \multirow{3}{*}{.501} \\
\hline & Spouse & 28 & & & & \\
\hline & Spouse and Children & 66 & & & & \\
\hline \multirow{2}{*}{ Insurance } & Not insured & 18 & & & \multirow{2}{*}{$r_{\mathrm{pb}}=.126$} & \multirow{2}{*}{.029} \\
\hline & Insured & 82 & & & & \\
\hline
\end{tabular}

In Table 2, we noted that as this particular population ages, they become more knowledgeable about heart disease risk factors $(p=.008)$. When looking at gender differences and knowledge, there were no significant differences between 
males and females $(p=.680)$. Also, there were no differences between employment status and heart disease knowledge $(p$ $=.717)$. However, significant differences were observed for marital status $(p=.012)$, education level $(p=.003)$, and participants who have or don't have insurance $(p=.029)$ and their knowledge scores. Those who were married, completed college, and have health insurance had higher knowledge scores compared to those who were not married, completed grade school and/or high school, or without health insurance.

\subsection{Self-reported heart disease risk factors}

The heart disease risk factors prevalent among first-generation Filipino Americans are displayed in Table 3.

Table 3. Heart disease risk factors among first-generation Filipino Americans ( $\mathrm{N}=300)$

\begin{tabular}{lll}
\hline Measure & Frequency & Percent \\
\hline Hypertension & 143 & 47.7 \\
Dyslipidemia & 83 & 27.7 \\
Type 1 Diabetes & 8 & 2.7 \\
Type 2 Diabetes & 35 & 11.7 \\
Lack of Exercise & 144 & 48.0 \\
Smoking & 35 & 11.7 \\
Overweight & 110 & 36.7 \\
${ }^{*}$ Abdominal obesity & 242 & 80.6 \\
\hline
\end{tabular}

Note. Frequency and percent answering "yes"

*: Actual waist circumference measurement based on 2006 International Diabetes Federation guideline for clinical definition of abdominal obesity

In a point-biserial correlation coefficient analysis of the data; age, and heart disease risk factors (HTN, dyslipidemia, type 1 diabetes, type 2 diabetes, smoking, and being overweight) served as continuous and dichotomous variables, respectively. There was a significant positive correlation between (a) age and $\operatorname{HTN}\left(r_{\mathrm{pb}}=.237, p<.001\right)$, (b) age and dyslipidemia (rpb $=.133, p=.021)$, and (c) age and type 2 diabetes $\left(r_{\mathrm{pb}}=.229, p<.001\right)$. The older they became, the more likely they were to develop one of these risk factors. For the remaining variables, there were no significant correlations $(p>.05)$.

\subsection{Demographic predictors for heart disease risk factors}

We found that participants with health insurance were 5.142 times more likely to have HTN than those without health insurance $(p=.001)$. Age was also found to be a predictor of HTN in participants aged 58-75, 32-41, and $42-49(p=.012$, $p=.001$, and $p=.008$, respectively). However, the younger the participants, the less likely they were to have HTN. For dyslipidemia, age was a significant predictor for disease within those aged 32-41 years $(p=.034)$. Age and other demographic data did not predict the likelihood of having type 2 diabetes. Gender $(p<.001)$ and age $(42-49, p=.039)$ were both found to be significant predictors for participating in regular exercise (32-41, results approached significance $p$ $=.054)$. Males were .5 times more likely to participate in regular exercise than females and those 32-49 were also .5 times more likely to participate in regular exercise compared to those who were older.

Both living alone, living with relatives and their children, or with a friend; and living with a spouse and children, were found to be predictors of smoking ( $p=0.37$ and $p=.014$, respectively). However, participants who lived with a spouse and children were 4.449 times more likely to smoke than those who lived alone, with relatives and children, or with a friend. Participants living with a spouse and children was also found to be a predictor for being overweight $(p=0.33)$. Participants were 2.109 times more likely to be overweight if they lived with a spouse and children compared to participants who lived alone, with relatives and their children, or with a friend. Living arrangement was also a predictor for abdominal obesity. 
Participants who lived alone, with a relative, children, or friend $(p=.028)$, with spouse only $(p=.011)$, and with a spouse and children $(p=.031)$, were all significant predictors for abdominal obesity.

When looking at living arrangement, those who "live alone" versus those who "live with" someone (i.e., spouse, children, friend), there are significant differences between participants with the heart disease risk factor for HTN between those who lived alone and those who lived with someone: $\chi^{2}(1, N=300)=4.97, p=.026$. However, there were no differences between those living alone and living with someone for all other heart disease risk factors.

\subsection{Predictors for heart disease knowledge}

The model as a whole explained $6.9 \%$ of the total variance in heart disease knowledge $\left(R^{2}=.069, F=7.359, p \leq .001\right)$ and demographics. However, only education level $(\beta=.157, t=2.744, p=.006)$, marital status $(\beta=.157, t=2.801, p=.005)$, and age $(\beta=.1297, t=2.256, p=.025)$ best predicted heart disease knowledge.

As a whole, the model explained $8.6 \%$ of the total variance in heart disease knowledge $\left(R^{2}=.086, F=14.022, p \leq .001\right)$ and heart disease risk factors. Exercise $(\beta=.282, t=5.007, p<.001)$, and abdominal obesity $(\beta=.144, t=2.553, p=.011)$ best predicted heart disease knowledge.

\section{Discussion}

Our study investigated the baseline knowledge of heart disease and the prevalence of heart disease risk factors among 300 first-generation Filipino Americans living in Southern Nevada. In general, the participants were knowledgeable about heart disease, as measured by their overall HDFQ score. Interestingly, many had at least one or a combination of the risk factors: HTN, diabetes, dyslipidemia, overweight, smoking, and lack of regular exercise. Although participants in this study had good knowledge of heart disease, they may not be aware of the specific actions to take to lower their heart disease risk. Additionally, they may not be aware of their own personal risk. Without an awareness of personal risk, individuals may not take action to decrease their risk of heart disease.

Our study showed that many Filipino Americans in this sample had HTN. This is consistent with previous reports ${ }^{[6,7,15]}$. Researchers have linked HTN to dietary lifestyle ${ }^{[7,15]}$. They implied that the Filipino diet is rich in sodium and that cooking practices are also a culprit. Smoking has been reported as a common problem among Filipinos ${ }^{[17,21]}$. In our study, however, only small number of participants reported they were smokers. Additionally, most of the participants were highly educated and many were college graduates. A study by Lenk and colleagues ${ }^{[22]}$ indicate that individuals with a four-year college degree were less likely to smoke than those who were not college graduates. Although education may have an impact on the prevalence of smoking, we cannot fully explain the decreased number of smokers in this sample.

According to the NHLBI ${ }^{[14]}$, men and women are at increased risk of heart disease by the time they reach middle-age (45 to 55 years). Since our sample had an average age of 50 years, the presence of heart disease risk factors in this population was to be expected. Our study also revealed that half of the sample did not participate in regular exercise. A possible explanation for the lack of exercise in this group could be the influence of western culture. Filipino Americans who migrate to the US become less physically active ${ }^{[24]}$. Most of their time is spent in sedentary activities, such as sitting or watching television ${ }^{[7,25]}$.

There is no single risk factor responsible for the onset of heart disease. For this reason, strategies to reduce risk factors or their severity are essential. Primary prevention programs that focus on diet, exercise, and the danger of heart disease should be emphasized. Lifestyle changes such as modifying dietary habits can benefit those who are at risk of developing risk factors. For example, the use of alternative ingredients, such as spices low in sodium instead of table salt, soy sauce, or fish sauce, can add flavor to food and help prevent HTN. The Dietary Approaches to Stop Hypertension (DASH) diet plan can be used as a starting point. Education regarding healthy ways to cook foods is also important. For example, the use of 
cooking oil sprays to fry certain dishes is healthier than the use of cooking oil containing saturate fats. Also, the avoidance of deep frying dishes such as eggrolls and crispy fried chicken or other meats should be emphasized. Lifestyle changes such as getting involved in an active lifestyle should be stressed. Education regarding the benefits of exercise is important as well as finding an activity that is enjoyable and sustainable is important. Exercise programs that are enjoyable and motivational have been shown to increase exercise participation and sustainability ${ }^{[26]}$. The involvement of the media (e.g. the Filipino television network) can tremendously help relay these messages specific to this population. With regard to individuals who smoke, referral to a smoking cessation program (with classes available in both English and Tagalog) and treatment such as the use of a nicotine replacement therapy ${ }^{[27]}$ may be considered to assist with smoking cessation for this population.

Since HTN, diabetes, and dyslipidemia are common problems among Filipino Americans, early screening for these conditions is crucial. Screening helps detect and help prevent complications arising from these conditions. For example, screening for diabetes using the glycohemoglobin A1C, in addition to a fasting blood glucose test, may enhance the detection of diabetes. Screening results may also prompt individuals to take action. Abdominal obesity can be detected during office visits by measuring the waist circumference using the International Diabetes Federation ${ }^{[23]}$ criteria. It may enhance the detection of abdominal obesity as it is specific to the Asian population.

In addition to lifestyle changes, pharmacological therapy can be started early for those who are newly diagnosed with HTN, or with prehypertension, to prevent development of heart disease ${ }^{[28,29]}$. Law and colleagues indicated that the use of hypertensive agents on prehypertensive individuals can reduce the risk of heart disease by $29 \%{ }^{[28]}$. Early pharmacological therapy may also be started for individuals with prediabetes, rather than relying only on lifestyle changes ${ }^{[30,31]}$.

\section{Limitation}

Our study should be interpreted cautiously. The results cannot be generalized to all Filipino Americans because of convenience sampling, self-report methods, and the small sample size and setting. Despite these limitations, our study provides important preliminary data. They reflect the baseline knowledge of heart disease among first-generation Filipino Americans living in Southern Nevada and the risk factors prevalent among this population.

\section{Conclusion}

Heart disease is the leading cause of death among Filipino Americans. Filipino Americans in this study had sufficient knowledge about heart disease. There was a contradiction, however, between their knowledge of heart disease and their application of this knowledge to preventing or reducing its risk factors. This important data may assist researchers in future studies. Because of the prevalence of heart disease among this population, early screening for HTN, diabetes, dyslipidemia, abdominal obesity, and other risk factors for heart disease should begin at an early age. Educational program targeting children and younger generation underscoring the role of diet and exercise should be emphasized. Health intervention strategies that respect the knowledge level, culture and beliefs of Filipino Americans should also be considered when designing programs as these may have profound effects in decreasing heart disease and improve the overall health of Filipino Americans.

\section{Acknowledgements}

This study is dedicated to the Filipino American community.

\section{Funding source}

This project was supported by grants from the National Center for Research Resources (5P20RR016464-11) and the National Institute of General Medical Sciences (8 P20 GM103440-11). 


\section{References}

[1] Hoeffel EM, Rastogi S, Kim MO, Shahid H. The Asian population: 2010. 2012. Avaible from: http://www.census.gov/prod/cen2010/briefs/c2010br-11.pdf

[2] United States Census Bureau News. Asian/Pacific American Heritage Month: May 2013. 2013. Available from: http://www.census.gov/newsroom/releases/pdf/cb13ff-09_asian.pdf

[3] Centers for Disease Control and Prevention. Leading causes of death. 2013. Available from: http://www.cdc.gov/nchs/fastats/lcod.htm

[4] Roger VL, Go AS, Lloyd-Jones DM, et al. Heart disease and stroke statistics--2011 update: a report from the American Heart Association. Circ. 2011; 123(4): e18-e209. http://dx.doi.org/10.1161/CIR.0b013e3182009701

[5] Dela Cruz FA, Lao BT, Heinlein C. Level of acculturation, food intake, dietary changes, and health status of first-generation Filipino Americans in Southern California. J Am Assoc Nurse Pract. 2013; 25(11): 619-629.

[6] Dalusung-Angosta A. CHD knowledge and risk factors among Filipino Americans connected to primary care services. J Am Assoc Nurse Pract. 2013; 25(9): 503-512.

[7] Dela Cruz FA, Galang CB. The illness beliefs, perceptions, and practices of Filipino Americans with hypertension. J Am Acad Nurse Pract. 2008; 20(3): 118-127. http://dx.doi.org/10.1111/j.1745-7599.2007.00301.x

[8] United States Department of Health \& Human Services; Cardiovascular risk in the Filipino community. Formative research from Daly City and San Francisco, California. 2013. Available from: http:/www.nhlbi.nih.gov/health/prof/heart/other/filipino.pdf

[9] Ye J, Rust G, Baltrus P, Daniels E. Cardiovascular risk factors among Asian Americans: results from a national health survey. Ann Epidemiol. 2009; 19: 718-723. http://dx.doi.org/10.1016/j.annepidem.2009.03.022

[10] Langenberg C, Araneta MRG, Bergstrom J, Marmot M, Barrett-Connor E. Diabetes and coronary heart disease in Filipino-American women: role of growth and life-course socioeconomic factors. Diabetes Care. 2007; 30: 535-541. http://dx.doi.org/10.2337/dc06-1403

[11] Araneta MRG, Barrett-Connor E. Subclinical coronary atherosclerosis in asymptomatic Filipino and white women. Circ. 2004; 110: 2817-2823. http://dx.doi.org/10.1161/01.CIR.0000146377.15057.CC

[12] Kim HS, Park SY, Grandinetti A, Holck PS, Waslien C. Major dietary patterns, ethnicity, and prevalence of type 2 diabetes in rural Hawaii. Nutr. 2008; 24: 1065-1072. http://dx.doi.org/10.1016/j.nut.2008.05.008

[13] Araneta MRG, Morton DJ, Lantion-Ang L, et al. Hyperglycemia and type 2 diabetes among Filipino women in the Philippines, Hawaii, and San Diego. Diabetes Res Clin Pract. 2006; 71: 306-312. http://dx.doi.org/10.1016/j.diabres.2005.07.012

[14] National Heart L, and Blood Institute. Who is at risk for coronary heart disease? 2012. Available from: http://www.nhlbi.nih.gov/health/health-topics/topics/cad/atrisk.html

[15] Ryan C, Shaw R, Pliam M, et al. Coronary heart disease in Filipino and Filipino-American patients: Prevalence of risk factors and outcomes of treatment. J Invasive Cardiol. 2000; 12: 134-139.

[16] Araneta MRG, Wingard DL, Barrett-Connor E. Type 2 diabetes and metabolic syndrome in Filpina American women. Diabetes Care. 2002;25:494-499. http://dx.doi.org/10.2337/diacare.25.3.494

[17] Maxwell AE, Garcia GM, Berman BA. Understanding tobacco use among Filipino American men. Nicotine Tob Res. 2007; 9: 769-776. http://dx.doi.org/10.1080/14622200701397890

[18] Maxwel AE, Bastani R, Vida P, Warda US. Strategies to recruit and retain older Filipino American immigrants for a cancer screening study. J Commun Health. 2005; 30(3): 167-179. http://dx.doi.org/10.1007/s10900-004-1956-0

[19] Wagner J, Lacey K, Chyun D, Abbott G. Development of a questionnaire to measure heart disease risk knowledge in people with diabetes: the Heart Disease Fact Questionnaire. Patient Educ Couns. 2005; 58: 82-87. http://dx.doi.org/10.1016/j.pec.2004.07.004

[20] Wagner J, Lacey K, Abbott G, De Groot M, Chyun D. Knowledge of heart disease risk in a multicultural community sample of people with diabetes. Ann Behav Med. 2006; 31: 224-230. http://dx.doi.org/10.1207/s15324796abm3103_3

[21] Maxwell AE, Bernaards CA, McCarthy WJ. Smoking prevalence and correlates among Chinese- and Filipino-American adults: findings from the 2001 California Health Interview Survey. Prev Med. 2005; 41: 693-699. http://dx.doi.org/10.1016/j.ypmed.2005.01.014

[22] Lenk K, Rode P, Fabian L, Bernat D, Klein E, Forster J. Cigarette use among young adults: comparisons between 2-year college students, 4-year college students, and those not in college. J Am Coll Health. 2012; 60: 303-308. http://dx.doi.org/10.1080/07448481.2011.607481

[23] International Diabetes Federation, 2006. Available from: http://www.idf.org/webdata/docs/IDF_Meta_def_final.pdf. 2012

[24] Choi SE, Chow VH, Chung SJ, Wong ND. Do risk factors explain the increased prevalence of type 2 diabetes among California Asian adults? J Immigr Minor Health. 2011; 13: 803-808. http://dx.doi.org/10.1007/s10903-010-9397-6 
[25] Ceria-Ulep CD, Dalusung-Angosta A, Magday-Asselstine RT, et al. Assessing physical activity and function in the Filipino older adults. J Cult Divers. 2013; 20: 30-39.

[26] Alpert PT. Alternative exercise may be attractive to more individuals. Home Health Care Manag Pract. 2010; 22: $301-304$. http://dx.doi.org/10.1177/1084822309357006

[27] Centers for Disease Control and Prevention. Quitting smoking among adults-United States, 2001-2010. 2011. Available from: http://www.cdc.gov/tobacco/data_statistics/mmwrs/byyear/2011/mm6044a2/intro.htm

[28] Law MR, Morris JK, Wald NJ. Use of blood pressure lowering drugs in the prevention of cardiovascular disease: Meta-analysis of 147 randomised trials in the context of expectations from prospective epidemiological studies. Br Med J. 2009; 338 : b1665.

[29] Fuchs FD. Prehypertension: The rationale for early drug therapy. Cardiovasc Therapeut. 2010; 28: 339-343. http://dx.doi.org/10.1111/j.1755-5922.2010.00167.x

[30] American Diabetes Association. Diagnosis and classification of diabetes mellitus. Diabetes Care. 2012; 35(suppl 1): S64-S71. http://dx.doi.org/10.2337/dc12-s064

[31] Zhang X, Gree EW, Williamson DF, et al. A1C level and future risk of diabetes: A systematic review. Diabetes Care. 2010; 33: 1665-1673. http://dx.doi.org/10.2337/dc09-1939 